\title{
Characteristics of TaFTSH6 Gene and Expression Analysis under Drought and Heat Stress in Wheat
}

Li Yuan ${ }^{1,2}$, Jiang Huijun ${ }^{1}$, Liu Jun ${ }^{2}$, Liu Yunguo ${ }^{1}$, Hu Xiaojun ${ }^{1} \square$

1 College of Life Science, Linyi University, Shandong Linyi, 276000, P.R. China

2 College of Life Science and Technology, Xinjiang University, Xinjiang Urumqi City, 830046, P.R. China

\ Corresponding author email: huxiaojun19812003@126.com

Triticeae Genomics and Genetics, 2021, Vol.12, No.1 doi: 10.5376/tgg.2021.12.0001

Received: 05 Jan., 2021

Accepted: 21 Nov., 2021

Published: 07 Dec., 2021

Copyright $\odot 2021$ Li et al., This article was first published in Molecular Plant Breeding in Chinese, and here was authorized to translate and publish the paper in English under the terms of Creative Commons Attribution License, which permits unrestricted use, distribution, and reproduction in any medium, provided the original work is properly cited.

Preferred citation for this article:

Li Y., Jiang H.J., Liu J., Liu Y.G., and Hu X.J., 2021, Characteristics of TaFTSH6 gene and expression analysis under drought and heat stress in wheat, Molecular Plant Breeding, 12(1): 1-10 (doi: 10.5376/tgg.2021.12.0001)

\begin{abstract}
In order to study the characteristics and functions of wheat FTSH genes, TaFTSH6 was cloned from wheat 'Bobwhite'. Phylogenetic tree analysis showed that the amino acid sequence was very similar to FTSH6 sequence of other species. SMART analysis showed that TaFTSH6 had a conserved N-terminal transmembrane domain, ATP binding sites and hydrophilic $\mathrm{Zn}^{2+}$ metalloproteinase domain. The gene was located on chr7D chromosome of wheat, named as TaFTSH6-7D. Cis-elements analysis of TaFTSH6 promoter sequence showed that there are several drought response sites CAACTG and a heat stress response site GACnnCTCnnGAA in the promoter, as well as many cis-elements related to hormone signal transduction. Quantitative expression analysis of TaFTSH6 gene in wheat seedlings under drought and heat stress showed that both drought and heat stress could increase the expression level of TaFTSH6 gene in root and leaf tissues, which indicated that TaFTSH6 was induced by drought and heat stress. Further study on the function of TaFTSH6 gene in wheat will partly support theoretical guidance to wheat breeding for drought and heat stress tolerance.
\end{abstract}

Keywords Wheat; TaFTSH6; Drought stress; Heat stress

FTSH (filamentation temperature-sensitive H) is a cytoplasmic membrane protein endopeptidase and belongs to the AAA (ATPase associated with diverse cellular activities) protease family (Ogura and Wilkinson, 2001). The family has an $\mathrm{N}$-terminal transmembrane domain, ATP and $\mathrm{Zn}^{2+}$ binding sites, forms complexes with regulatory factor $H f l K$ or $H f l C$ oligomers in the form of cyclic homohexamer, and relies on ATP to degrade short-lived proteins and misassembled membrane proteins, so as to regulate the normal growth and development of organisms (Kihara et al., 1997; Kihara and Ito, 1998; Ito and Akiyama, 2005). FTSH is necessary for the growth of many organisms. The decrease of gene expression or gene mutation of this family will lead to serious growth defects and even death of Bacillus subtilis and Escherichia coli (Deuerling et al., 1997; Jayasekera et al., 2000). FTSH gene was first independently discovered by 4 different research groups when screening different phenotypes in Escherichia coli (Schumann, 1999). So far, it has been found and studied in a variety of organisms such as Bacillus subtilis (Deuerling et al., 1995), Lactococcus lactis (Duwat et al., 1995), Arabidopsis thaliana (Lindahl et al., 1996), Nicotiana tabacum (Seo et al., 2000), Medicago sativa (Ivashuta et al., 2002), Citrullus lanatus (Akashi et al., 2004), Synechocystis sp (Kamata et al., 2005), Solanum lycopersicum (Sun et al., 2006a), Zea mays (Andjelkovic and Thompson 2006), Spinacia oleracea (Yoshioka et al., 2006), Brassica juncea (Knight et al., 2006), Solanum tuberosum (Fan et al., 2007), Xerophyta viscose (Ingle et al., 2007), Oryza sativa (Zhang and Sun, 2009), Glycine max (Yin et al., 2011), Lactobacillus plantarum (Bove et al., 2012), Arachis hypogaea (Zheng et al., 2016, Jiangsu Agricultural Sciences, 44(12): 74-77) and Acidovorax citrulli (Ji et al., 2019).

FTSH was involved in the response of organisms to a variety of stress. Heat stress or light stress increased the expression of FTSH gene in Synechocystis $s p$ cells (Kamata et al., 2005). Lactobacillus plantarum mutants lacking FTSH protease showed significant sensitivity to the increase of heat and salt concentration, while FTSH overexpression led to the increase of heat and salt stress tolerance (Bove et al., 2012). The growth ability of the 
FTSH gene deletion mutant of Acidovorax citrulli was significantly reduced under heat stress and high salt stress (Ji et al., 2019). It was also found that FTSH was involved in resisting stress responses such as cold stress, heat stress, drought stress and salt stress. Stress could increase the expression of FTSH gene. For example, cold stress increased the expression of MsFTSH gene in Medicago sativa (Ivashuta et al., 2002); Heat stress increased the expression of AtFTSH11 gene in Arabidopsis thaliana (Chen et al., 2006) and LeFTSH6 gene in Solanum lycopersicum (Sun et al., 2006b); Drought stress significantly increased the expression of SoFTSH4-like gene in leaves and roots of Solanum tuberosum (Fan et al., 2007); Salt stress up-regulated the expression of 9 FTSH gene in Arachis hypogaea, including one FTSH6-like gene (Zheng et al., 2016). FTSH gene can improve the tolerance of plants to stress. Overexpression of AtFTSH11 in Arabidopsis thaliana contributed to the overall tolerance to heat stress (Chen et al., 2006); FTSHi5 can inhibit the expression of aging related genes and maintain cell redox balance (Wang et al., 2018b; Havé et al., 2018). However, there was no report on the application of FTSH gene in wheat.

Wheat is an important food crop in the world. In different regions of the world, wheat is often subjected to drought and heat stress throughout its growth period, and its yield and quality are seriously affected. Therefore, improving the drought and heat resistance of wheat is of great significance to the high and stable yield and high quality of wheat. In order to study the characteristics and functions of wheat FTSH genes, TaFTSH6 was cloned from wheat 'Bobwhite', and its expression changes under drought and heat stress were analyzed by bioinformatics to provide a theoretical basis for wheat drought and heat resistance and provide a new idea for wheat breeding for drought and heat stress tolerance.

\section{Results and Analysis}

\subsection{TaFTSH6 gene cloning and evolutionary tree analysis of amino acid sequence}

Using wheat leaf cDNA as template, TaFTSH6F and TaFTSH6R were used for PCR amplification. The amplification products were detected by $1 \%$ agarose gel electrophoresis. The gene fragment larger than $2000 \mathrm{bp}$ was observed (Figure 1), which was consistent with the expectation. The target fragment was recovered, purified and connected with pMD19-T vector to transform E. coil DH5 $\alpha$ competent cells, the transformed products were screened by colony PCR for positive clones, and the plasmids were extracted and sent to BGI for sequencing. The sequence has an ORF of $2049 \mathrm{bp}$ and encodes 683 amino acids. The gene sequence was compared on the wheat gene bank URGI, and it was found that the gene was located on the chr7D chromosome, so it was named TaFTSH6-7D.

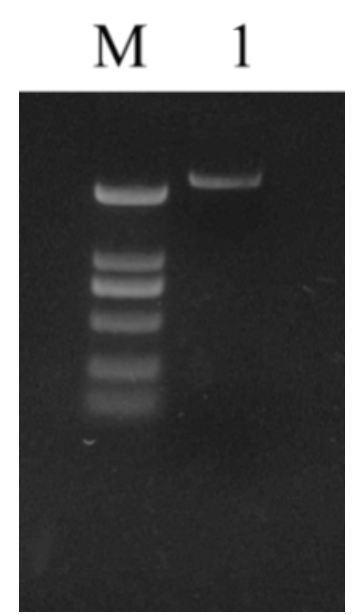

Figure 1 Amplification products of TaFTSH6-7D PCR

Note: M: DL 2000 Marker; 1: PCR product of TaFTSH6-7D ORF

The evolutionary tree analysis of FTSH amino acid sequences of different species showed that TaFTSH6 sequence was highly similar to FTSH6 of other species, and FTSH6 sequence also showed obvious differences between 
monocotyledons and dicotyledons (Figure 2). TaFTSH6-7D had the highest homology with its diploid ancestor Aegilops auschii, up to 99\%, and was slightly different from TaFTSH6-7A and TaFTSH6-7B. Moreover, TaFTSH6-7D was closely related to Hordeum vulgare, Brachypodium distachyon, Oryza sativa, Sorghum bicolor and Zea mays, and far from FTSH6 of other species.

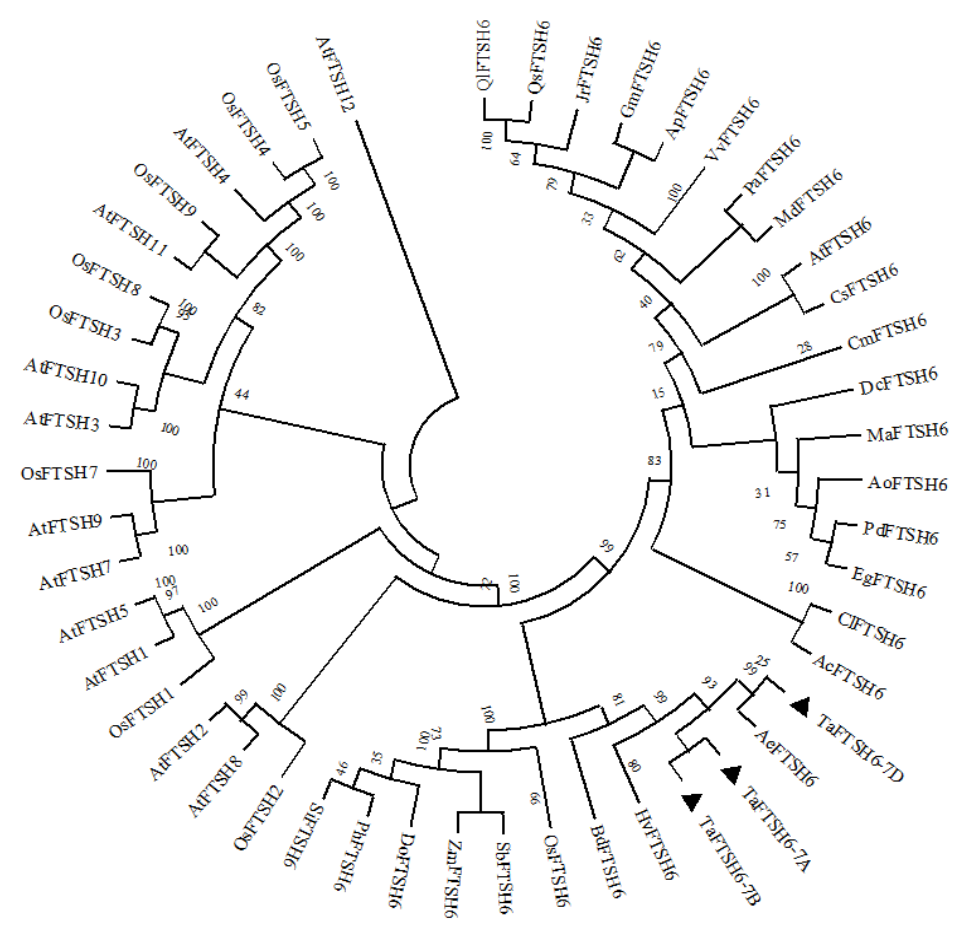

Figure 2 Evolutionary tree analysis of FTSH6

Note: the access number and Latin name of the proteins and their species in the figure are as follows: QIFSTH6(Quercu lobatas; XP_030954247.1); QsFTSH6 (Quercus suber; XP_023912746.1); JrFSTH6 (Juglans regia; XP_018813999.1); GmFSTH6 (Glycine max; XP_003552529.1); ApFSTH6 (Abrus precatorius; XP_027351682.1); VvFSTH6 (Vitis vinifera; XP_002283393.2); PaFSTH6 (Prunus avium; XP_021812467.1); MdFSTH6 (Malus domestica; XP_028963645.1); AtFSTH6 (Arabidopsis thaliana; NP_568311.2); CsFSTH6 (Citrus sinensis; XP_006482602.1); CmFSTH6 (Cinnamomum micranthum; RWR84016.1); DcFSTH6 (Dendrobium catenatum; XP_020697708.1); MaFSTH6 (Musa acuminata; XP_009381413.1); AoFSTH6 (Asparagus officinalis; XP_020255491.1); PdFSTH6 (Phoenix dactylifera; XP_008802626.1); EgFSTH6 (Elaeis guineensis; XP_010939484.1); ClFSTH6 (Carex littledalei; KAF3329191.1); AcFSTH6 (Ananas comosus; OAY79220.1); AeFSTH6 (Aegilops tauschii; XP_020164802.1); HvFSTH6 (Hordeum vulgare; KAE8798980.1); BdFSTH6 (Brachypodium distachyon; XP_003564049.1); OsFSTH6 (Oryza sativa; XP_015641788.1); SbFSTH6 (Sorghum bicolor; XP_002438106.1); ZmFSTH6 (Zea mays; ACG28886.1); DoFSTH6 (Dichanthelium oligosanthes; OEL32993.1); PhFSTH6 (Panicum hallii; XP_025812318.1); SiFSTH6 (Setaria italica; XP_004965045.1); OsFTSH2 (Oryza sativa; XP_015643053.1); AtFTSH8 (Arabidopsis thaliana; NP_563766.3); AtFTSH2 (Arabidopsis thaliana; XP_015643053.1); OsFTSH1 (Oryza sativa; XP_015643811.1); AtFTSH1 (Arabidopsis thaliana; NP_564563.1); AtFTSH5 (Arabidopsis thaliana; NP_568604.1); AtFTSH7 (Arabidopsis thaliana; NP_566889.1); AtFTSH9 (Arabidopsis thaliana; NP_568892.1); OsFTSH7 (Oryza sativa; XP_015625409.1); AtFTSH3 (Arabidopsis thaliana; NP_850129.1); AtFTSH10 (Arabidopsis thaliana; NP_172231.2); OsFTSH3 (Oryza sativa; XP_015626112.1); OsFTSH8 (Oryza sativa; XP_015639995.1); AtFTSH11 (Arabidopsis thaliana; NP_568787.1); OsFTSH9 (Oryza sativa; XP_015621895.1); AtFTSH4 (Arabidopsis thaliana; NP_565616.1); OsFTSH4 (Oryza sativa; XP_015621656.1); OsFTSH5 (Arabidopsis thaliana; XP_015615459.1); AtFTSH12 (Arabidopsis thaliana; NP_565212.1)

\subsection{Structural analysis of TaFTSH6 protein}

By comparing the TaFTSH6 protein sequence of wheat with that of Oryza sativa, Hordeum vulgare and Zea mays, it was found that the FTSH6 sequence was highly conserved and had the typical characteristics of FTSH family, especially between $90 \sim 670$ aa. It showed a conserved N-terminal transmembrane domain at 164 182. There were typical ATP binding sites at 260 268, 315 320 and 360 366. The conserved WalkerA domain GXXGXGK (S/T) 
was located at 260 268, and the conserved WalkerB domain VFIDE was located at 315 320. Behind the ATP binding site, there was a typical LLRXGRX arginine ring structure (at 375 381) (Figure 3).

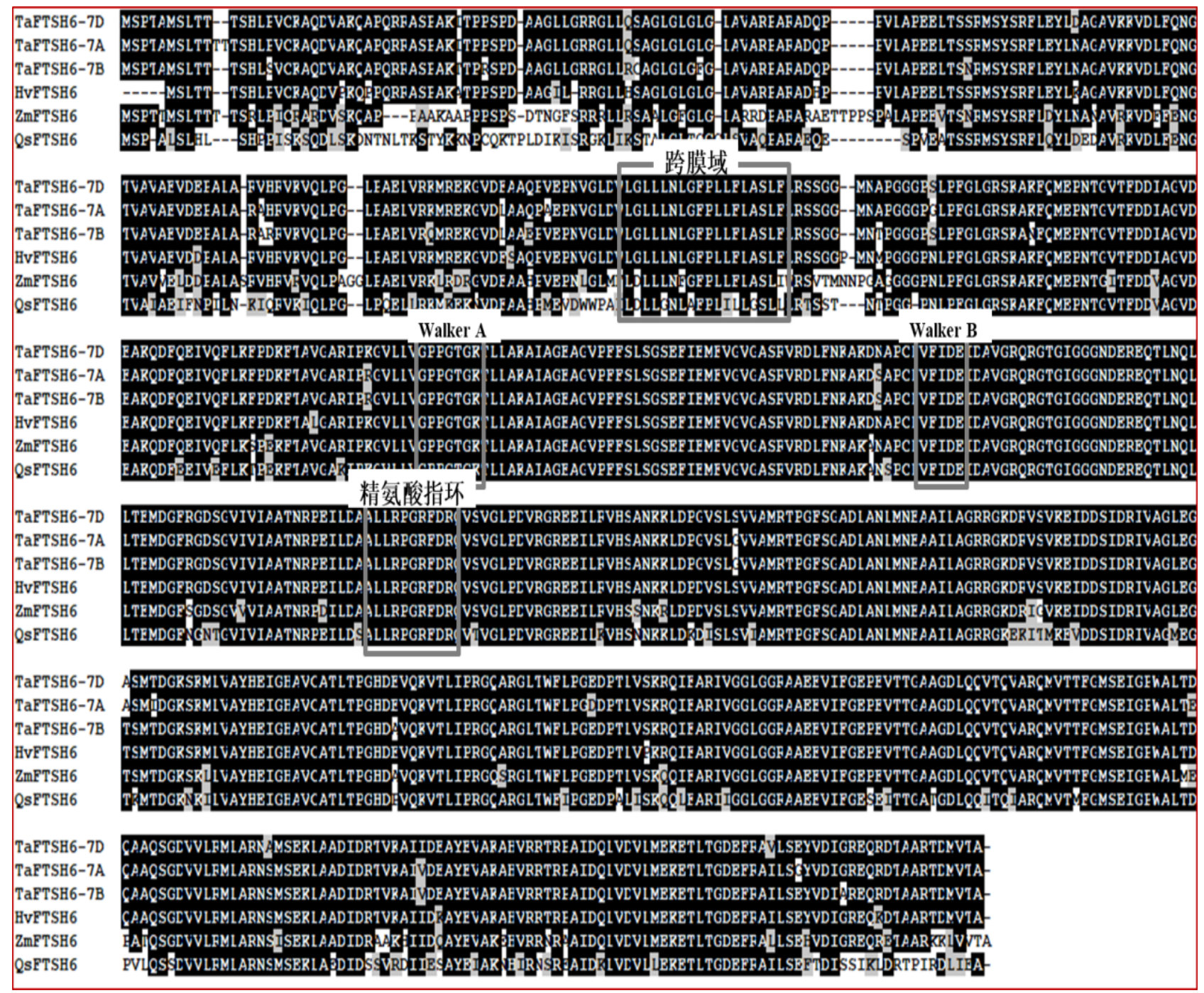

Figure 3 ClustalW analysis of FTSH6 among different species

Note: HvFSTH6, OsFSTH6 and ZmFSTH6 are amino acid sequences of FTSH6 protein of barley, rice and maize, and the access numbers are KAE8798980.1, and XP_015641788.1 and ACG28886.1 respectively

\subsection{Cis-elements analysis of TaFTSH6 promoters}

The promoter sequence in the region about $2 \mathrm{~kb}$ upstream of the start codon of TaFTSH6-7D gene coding region was analyzed. The results showed that CAACTG drought response site was found at $56 \mathrm{bp}, 339 \mathrm{bp}, 1101 \mathrm{bp}$ and $1833 \mathrm{bp}$ upstream of ATG, and GACnnCTCnnGAA heat shock transcription factor binding site was found at 234 bp upstream of ATG. In addition, there were many cis-acting regulatory elements involved in growth and development, cis-acting regulatory elements involved in hormone signal transduction pathway and cis-acting regulatory elements involved in abiotic stress response in the promoter region of TaFTSH6-7D gene (Table 1).

\subsection{The expression analysis of TaFTSH6-7D gene under drought and heat stress}

In order to study the response of TaFTSH6-7D gene to drought and heat stress, the expression of TaFTSH6 gene in leaves and roots of wheat at seedling stage was analyzed by RT-PCR. The results showed that under drought stress, the expression of TaFTSH6-7D gene in leaves and roots of wheat increased, especially after 12 hours of treatment, the expression of TaFTSH6-7D gene increased significantly and extremely significantly in leaves and roots, respectively. Under heat stress, the expression of TaFTSH6-7D gene in leaves and roots of wheat also increased. 
At $6 \mathrm{~h}, 2 \mathrm{~d}(6 \mathrm{~h} / \mathrm{d})$ and $3 \mathrm{~d}(6 \mathrm{~h} / \mathrm{d})$, the expression of TaFTSH6-7D gene increased significantly in leaves and roots. The above results showed that TaFTSH6-7D gene was induced by drought and heat stress.

Table 1 Cis-elements analysis of TaFTSH6-7D promoters

\begin{tabular}{|c|c|c|c|}
\hline Name & Position & Function & Sequence \\
\hline AAGAA-motif & $25-, \quad 1409-$ & $\begin{array}{l}\text { Cis-acting element involved in the } \\
\text { abscisic acid responsiveness }\end{array}$ & GAAAGAA \\
\hline $\mathrm{ABRE}$ & $\begin{array}{l}1595+, 95+, \\
230+, 190+, 231+\end{array}$ & $\begin{array}{l}\text { Cis-acting element involved in the } \\
\text { abscisic acid responsiveness }\end{array}$ & ACGTG, CACGTG \\
\hline $\mathrm{ACE}$ & 796- & $\begin{array}{l}\text { Cis-acting element involved in light } \\
\text { responsiveness }\end{array}$ & CTAACGTATT \\
\hline ARE & $402+, 1777+, 564-$ & $\begin{array}{l}\text { Cis-acting regulatory element } \\
\text { essential for the anaerobic induction }\end{array}$ & AAACCA \\
\hline Box 4 & $36+$ & $\begin{array}{l}\text { Part of a conserved DNA module } \\
\text { involved in light responsiveness }\end{array}$ & ATTAAT \\
\hline C-box & $1821+$ & $\begin{array}{l}\text { Cis-acting regulatory element } \\
\text { involved in light responsiveness }\end{array}$ & ACGAGCACCGCC \\
\hline CAT-box & $1471+, 1950+, 1500+$ & $\begin{array}{l}\text { Cis-acting regulatory element related } \\
\text { to meristem expression }\end{array}$ & GCCACT \\
\hline CCAAT-box & $857+$ & MYBHv1 binding site & CAACGG \\
\hline CGTCA motif & 956-, $1834+$ & $\begin{array}{l}\text { Cis-acting regulatory element } \\
\text { involved in the MeJA-responsiveness }\end{array}$ & CGTCA \\
\hline G-Box & $\begin{array}{l}94-, 230+, 189-, 1594-, 1592+, \\
1750-\end{array}$ & $\begin{array}{l}\text { Cis-acting regulatory element } \\
\text { involved in light responsiveness }\end{array}$ & $\begin{array}{l}\text { CACGTT, CACGTC, } \\
\text { GCCACGTGGA, CACGAC }\end{array}$ \\
\hline GATA-motif & $1491+$ & Part of a light responsive element & AAGGATAAGG \\
\hline GC-motif & $1617-, \quad 1682+$ & $\begin{array}{l}\text { Enhancer-like element involved in } \\
\text { anoxic specific inducibility }\end{array}$ & CCCCCG \\
\hline GT1-motif & $909+$ & Light responsive element & GGTTAA \\
\hline I-box & $1492-, \quad 1493+$ & Part of a light responsive element & ССТTATCCT 、 GTATAAGGCC \\
\hline MBS & $268-, 1662+, 900-, 1945-$ & $\begin{array}{l}\text { MYB binding site involved in } \\
\text { drought-inducibility }\end{array}$ & CAACTG \\
\hline MYB & $\begin{array}{ll}661-, & 1300-, \\
768-, & 1081-\end{array}$ & MYB response element & CAACCA, TAACCA \\
\hline MYB recognition site & $857-$ & MYB response element & CCGTTG \\
\hline MYB-like sequence & 908-, 1333- & MYB response element & TAACCA \\
\hline MYC & $\begin{array}{l}615-, 1537+, 1205-, 693-, \\
1221+\end{array}$ & MYC response element & CATGTG \\
\hline Myb & 248-, 1945-, 900-, 509-, 1662+ & MYB response element & CAACTG \\
\hline P-box & 394 & Gibberellin-responsive element & CCTTTTG \\
\hline RY-element & 726 & $\begin{array}{l}\text { Cis-acting regulatory element } \\
\text { involved in seed-specific regulation }\end{array}$ & CATGCATG \\
\hline Sp1 & $1674-, \quad 1679-$ & Light responsive element & GGGCGG \\
\hline TATC-box & $610+$ & $\begin{array}{l}\text { Cis-acting element involved in } \\
\text { gibberellin-responsiveness }\end{array}$ & TATCCCA \\
\hline TC-rich repeats & 1044 & $\begin{array}{l}\text { Cis-acting element involved in } \\
\text { defense and stress responsiveness }\end{array}$ & СТТТТСТТАС \\
\hline TCA-element & $1480+$ & $\begin{array}{l}\text { Cis-acting element involved in } \\
\text { salicylic acid responsiveness }\end{array}$ & ССАТСТTТTТ \\
\hline TCT-motif & $272+, 1048+, 375-$ & Part of a light responsive element & TCTTAC \\
\hline TGA-element & $1385+$ & Auxin-responsive element & AACGAC \\
\hline TGACG-motif & $956+, 1834-$ & $\begin{array}{l}\text { Cis-acting regulatory element } \\
\text { involved in the MeJA-responsiveness }\end{array}$ & TGACG \\
\hline
\end{tabular}




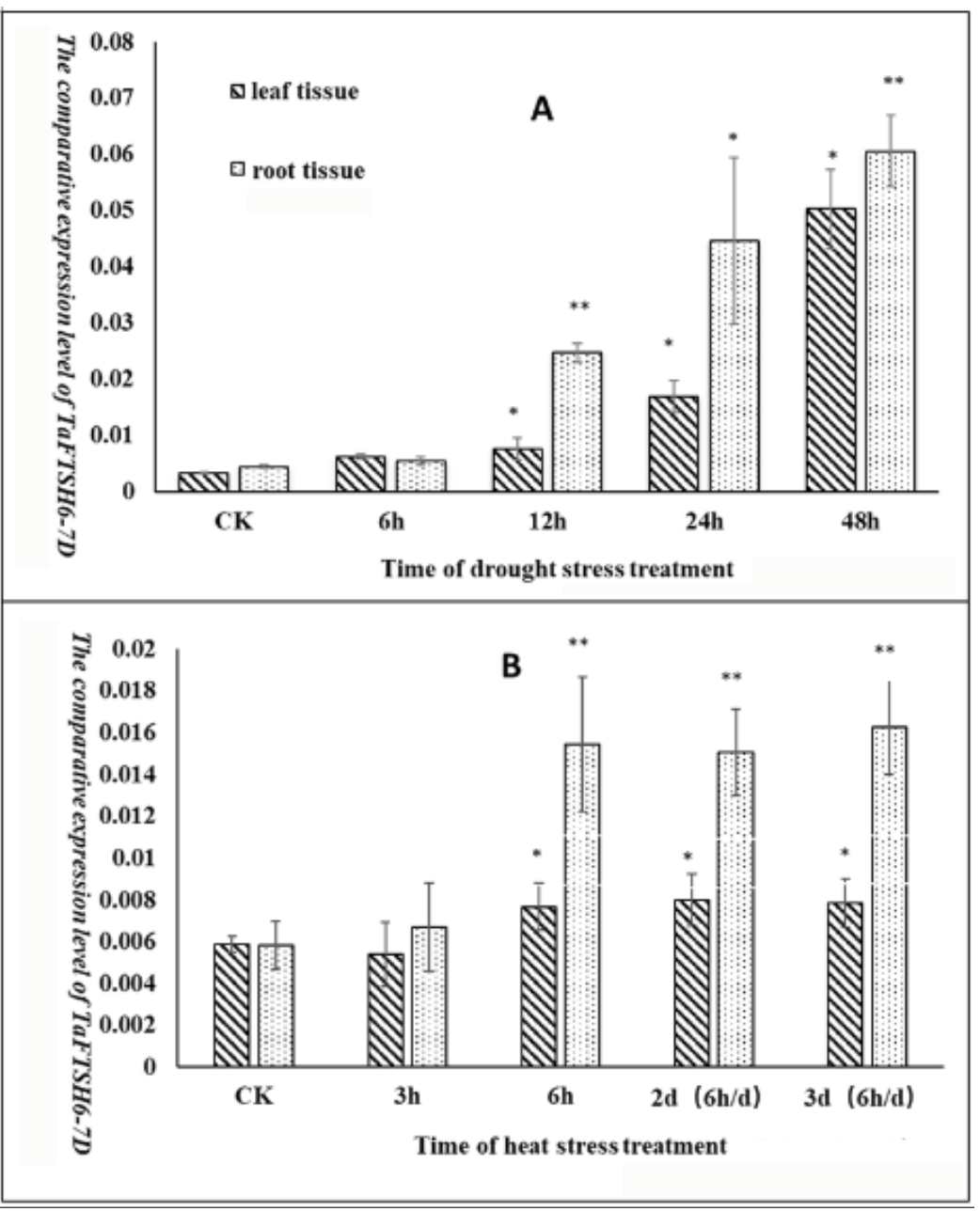

Figure 4 Expression profile of TaFTSH6-7D gene under drought and heat stress

Note: Panel A is the change of TaFTSH6-7D gene expression under drought treatment; Panel B is the change of TaFTSH6-7D gene expression under heat stress

\section{Discussion}

Plants face a variety of abiotic and biotic stresses throughout their life cycle, and protein degradation in vivo is one of the important ways for plants to respond to environmental stress and coordinate the relationship between growth and stress response (Chen et al., 2020). Organisms degrade end-of-life proteins and misassembled membrane proteins to regulate the normal growth and their response to the environment (Wang et al., 2018a). There are mainly ATP-independent lysosomal pathway and ATP-dependent ubiquitin proteasome pathway for protein degradation in organisms. Recent studies have also found the caspase pathway, the La protease pathway of mitochondria, the Kex2 hydrolase pathway in the Golgi body, and the hydrolase pathway on the cell membrane surface (Ling et al., 2019). Protein degradation by FTSH protease depends on ATP to provide energy. In Escherichia coli, FTSH forms complexes with the regulator $H f 1 K C$ oligomer in the form of cyclic homo-hexamer, and its activity is modified by phosphorylation (Kato and Sakamoto, 2019), and it degrade short-lived proteins and misassembled proteins (Nishimura et al., 2016). Its special feature is that it is membrane anchored, which can degrade wrong proteins and maintain membrane stability under stress conditions (Kato and Sakamoto, 2018). It is a hydrolase on the surface of cell membrane. Therefore, the FTSH protease family has an N-terminal transmembrane domain and a $\mathrm{C}$-terminal region extending into the matrix. The $\mathrm{C}$-terminal region contains ATPase and protease domain. ATPase domain plays the function of unfolding enzyme and transfers the substrate to the protease domain degradation chamber through a narrow pore. This study found that the FTSH6 protein sequences of different species were highly conserved in the $\mathrm{N}$-terminal transmembrane domain, the C-terminal ATP binding site and the arginine ring. 
At present, the mechanism of FTSH protease is still poorly understood. FTSH protease can extract and degrade the intact membrane protein from the membrane (Kato and Sakamoto, 2018). There are 12 FTSH coding genes in Arabidopsis thaliana, and 9 of them are located on the thylakoid membrane of the chloroplasts, 3 are located on the mitochondrial membrane (Sakamoto et al., 2003). FTSH is involved in the formation of thylakoid membrane during the early development of chloroplasts. The FTSH mutation in Nicotiana tabacum caused the collapse of thylakoid membrane in the later stages of leaf development (Kato et al., 2012). In addition, FTSH is also involved in the degradation and assembly of D1 protein in photosystem II repair cycle and several protein complexes in photosynthetic electron transport pathway. In Arabidopsis thaliana mutants lacking FTSH, light-damaged D1 protein accumulated, ROS (reactive oxygen species) signals were not effectively transmitted, and showed higher sensitivity to strong light stress (Zaltsman et al., 2005; Dogra et al., 2017; Wang et al., 2018a). However, the regulation mode of protease activity of FTSH, the pattern of FTSH and its complex recognizing damaged proteins, and the specific function and function mode of FTSH need to be further studied.

FTSH has been reported to be involved in the response to drought and heat stress. Under drought conditions, the increase of FTSH gene expression or a large amount of FTSH protein synthesis were found in plants such as Xerophyta viscose (Ingle et al., 2007), Citrullus lanatus originated from African desert (Akashi et al., 2004), Zea mays (Andjelkovic and Thompson, 2006), Brassica juncea (Knight et al., 2006) and Solanum tuberosum (Fan min et al., 2007). The increase of FTSH gene expression in the roots of Oryza sativa can enhance drought stress tolerance (Zhang and sun, 2009). Heat stress can increase the expression of LeFTSH6 gene in Solanum lycopersicum (Sun et al., 2006a; 2006b). Overexpression of FTSH11 in Arabidopsis thaliana contributed to the overall tolerance to heat stress (Chen et al., 2006). In wheat, it was found that the expression of FTSH2 in heat-resistant varieties was significantly higher than that in heat sensitive varieties under heat stress (Wang et al., 2015). In this study, it was found that the expression of TaFTSH6-7D gene in wheat increased significantly under PEG simulated drought or $36^{\circ} \mathrm{C}$ heat treatment at seedling stage, which was consistent with the reports about other plants. The results of this study showed that TaFTSH6-7D gene was induced by drought and heat stress. The further study on the function and regulation mode of TaFTSH6 gene will provide a theoretical guidance to wheat molecular breeding for drought and heat stress tolerance.

\section{Materials and Methods}

\subsection{Plant materials and treatment}

In the light incubator, the seeds of wheat (Triticum aestivum L.) variety 'Bobwhite' were cultured in the medium at $4^{\circ} \mathrm{C}$ for $5 \mathrm{~d}, 12^{\circ} \mathrm{C}$ for $5 \mathrm{~d}$ and $25^{\circ} \mathrm{C}$ for $2 \mathrm{~d}$, and then transferred to $1 / 2 \mathrm{MS}$ medium and cultured until three leaf stage under the conditions of $25^{\circ} \mathrm{C}(16 \mathrm{~h}) / 20^{\circ} \mathrm{C}(8 \mathrm{~h})$ (day/night) and $75 \%$ relative humidity. The seedlings were subjected to simulated drought (15\% PEG, $6 \mathrm{~h}, 12 \mathrm{~h}, 24 \mathrm{~h}$ and $48 \mathrm{~h})$, heat $\left(36^{\circ} \mathrm{C}, 3 \mathrm{~h}, 6 \mathrm{~h}, 2 \mathrm{~d}(6 \mathrm{~h} / \mathrm{d})\right.$ and $3 \mathrm{~d}(6$ $\mathrm{h} / \mathrm{d})$ ) stress, and compared with normal growing seedlings. The samples were frozen in liquid nitrogen and stored at $-80^{\circ} \mathrm{C}$.

\subsection{RNA extraction and cDNA synthesis}

The total RNA was extracted from wheat leaves and roots by Trizol method, and the plants extracted RNA were seedlings and in good growth condition. After removing DNA from RNA samples, cDNA was synthesized according to the instructions of one-step reverse transcription kit from Tiangen Company and stored at $-20^{\circ} \mathrm{C}$.

\subsection{Primer design and PCR amplification}

The primers used in this experiment were shown in Table 2. TaFTSH6F and TaFTSH6R were used for gene cloning. The PCR reaction procedure was as follows: pre-denaturation at $94^{\circ} \mathrm{C}$ for $5 \mathrm{~min}$, denaturation at $94^{\circ} \mathrm{C}$ for $45 \mathrm{~s}$, annealing at $60^{\circ} \mathrm{C}$ for $45 \mathrm{~s}$, extension at $72^{\circ} \mathrm{C}$ for $120 \mathrm{~s}$, as to the first five cycles, the annealing temperature of each cycle was $1^{\circ} \mathrm{C}$ lower than that of the previous one, and after reducing to $55^{\circ} \mathrm{C}, 30$ cycles need to be performed, and then extended at $72^{\circ} \mathrm{C}$ for $10 \mathrm{~min}$, and finally kept at $12^{\circ} \mathrm{C}$. The ABI Stepone plus quantitative PCR instrument was used for fluorescence quantitative PCR, and the operation was carried out according to the instructions of SYBR Green PCR Master Mix (Applied biosystems) kit. In order to ensure the specificity of 
primers, the 3'- end primers were designed in untranslated sequences, the specificity of primers was checked on the Wheat Gene Index database (http://blast.jcvi.org/euk-blast/index.cgi?project=tae1) website, and the melting curve presented a single peak. The expression of housekeeping gene TaRP15 did not change under drought and heat stress. Three replicates were set up.

Table 2 Primers sequences listed

\begin{tabular}{ll}
\hline Primer & Sequence \\
\hline TaFTSH6F & 5'-ATGTCGCCCACGGCCATGTCGC-3' \\
TaFTSH6R & 5'-TCAAGCAGTGACCATGTCCGTC-3' \\
TaFTSH6-Q7DF & 5'-ACGTGCTCATGGAGAAGGAGAC-3' \\
TaFTSH6-Q7DR & 5'-CCTACCACAGTCTGCACTACACAA-3' \\
TaRP15-F & 5'-CGGGATCGGAGTAATGA-3' \\
TaRP15-R & 5'-TTCGCAGTTGTTCGTCTT-3' \\
\hline
\end{tabular}

\subsection{Bioinformatics analysis}

the URGI (https://urgi.versailles.inra.fr/blaST/?dbgroup=wheat_all\&program=blaSTn) was used for obtaining the physical location of TaFTSH6 gene based on the known sequence of wheat. According to the obtained positioning, cDNA sequences were obtained from (http://202.194.139.32/). The intron exon analysis of TaFTSH6 gene was performed in FGENESH HMM based Gene Structure prediction of Softberry. The FTSH6 sequences of other species were searched through BLASTX (http://www.ncbi. nlm.nih.gov/) on NCBI website. In MEGA10.0, ClustalW method was used for multi sequence alignment analysis, and then neighbor-joining method (bootstrap=1000) was used to construct evolutionary tree. The transmembrane domain analysis was performed on (http://www.cbs.dtu.dk/services/TMHMM-2.0/). The analysis of cis-acting elements of promoter was performed on (http://bioinformatics.psb.ugent.be/webtools/plantcare/html).

\section{Authors' contributions}

LY was the executor of this study, completing data analysis and writing the first draft of the manuscript; JHJ participated in designing the experiments and analyzing the results; LJ and LYG were the conceivers of the project. HXJ directed the experimental design, data analysis, manuscript writing and revision. All authors read and approved the final manuscript.

\section{Acknowledgments}

This study was jointly funded by Public Welfare Projects of Key Research and Development in Shandong Province (No.2017NC210010) and National Key Research and Development Projects in China (No.2017YFD0301003).

\section{References}

Akashi K., Nishimura N., Ishida Y., and Yokota, A., 2004, Potent hydroxyl radical-scavenging activity of drought-induced type-2 metallothionein in wild watermelon, Biochemical \& Biophysical Research Communications, 323(1): 72-78 https://doi.org/10.1016/j.bbrc.2004.08.056

Andjelkovic V., and Thompson R., 2006, Changes in gene expression in maize kernel in response to water and salt stress, Plant Cell Reports, 25(1): 71-79 https://doi.org/10.1007/s00299-005-0037-X

Bove P., Capozzi V., Garofalo C., Rieu A., Spano G., and Fiocco D., 2012, Inactivation of the FTSH gene of Lactobacillus plantarum WCFS1: effects on growth, stress tolerance, cell surface properties and biofilm formation, Microbiological Research, 167(4): 187-193 https://doi.org/10.1016/i.micres.2011.07.001

Chen J., Burke J.J., Velten J., and Xin Z., 2006, FTSH11 protease plays a critical role in Arabidopsis thermotolerance, Plant Journal for Cell \& Molecular Biology, 48(1): 73-84 https://doi.org/10.1111/i.1365-313X.2006.02855.X

Chen Q., Yu F., and Xie Q., 2020, Insights into endoplasmic reticulum-associated degradation in plants, New Phytologist, 226(2): 345-350 https://doi.org/10.1111/nph.16369

Deuerling E., Paeslack B., and Schumann W., 1995, The FTSH gene of Bacillus subtilis is transiently induced after osmotic and temperature up shock. Journal of Bacteriology, 177(14): 4105-4112 https://doi.org/10.1128/jb.177.14.4105-4112.1995

Deuerling E., Mogk A., Richter C., Purucker M., and Schumann W., 1997, The FTSH gene of Bacillus subtilis is involved in major cellular processes such as sporulation, stress adaptation and secretion, Molecular Microbiology, 23(5): 921-933 https://doi.org/10.1046/j.1365-2958.1997.2721636.x 
Dogra V., Duan J., Lee K.P., Lv S., Liu R., and Kim C., 2017, FTSH2-dependent proteolysis of EXECUTER1 is essential in mediating singlet oxygen-triggered retrograde signaling in Arabidopsis thaliana, Frontiers in Plant Science, 8: 1145 https://doi.org/10.3389/fpls.2017.01145

Duwat P., Ehrlich S.D., and Gruss A., 1995, The recA gene of Lactococcus lactis: characterization and involvement in oxidative and thermal stress, Molecular Microbiology, 17(6): 1121-1131 https://doi.org/10.1111/j.1365-2958.1995.mmi 17061121.x

Fan M., Jin L.P., Huang S.W., Xie K. Y., Liu Q C., and Qun D Y, 2007, Cloning and expression of a full-length cDNA of SoFTSH gene in potato under drought stress, Acta Agronomica Sinica, 33 (11): 1748-1754

Havé M., Balliau T., Cottyn-Boitte B., Dérond E., Cueff G., Soulay F., Lornac A., Reichman P., Dissmeyer N., Avice J.C., Gallois P., Rajjou L., Zivy M., and Masclaux-Daubresse C., 2018 , Increases in activity of proteasome and papain-like cysteine protease in Arabidopsis autophagy mutants: back-up compensatory effect or cell-death promoting effect? Journal of Experimental Botany, 69(6): 1369-1385 https://doi.org/10.1093/jxb/erx482

Ingle R.A., Schmidt U.G., Farrant J.M., Thomson J.A., and Mundree S.G., 2007, Proteomic analysis of leaf proteins during dehydration of the resurrection plant Xerophyta viscose, Plant Cell Environment, 30(4): 435-446 https://doi.org/10.1111/j.1365-3040.2006.01631.x

Ito K., and Akiyama Y., 2005, Cellular functions, mechanism of action, and regulation of FTSH protease, Annual Review of Microbiology, 59(1): 211-231 https://doi.org/10.1146/annurev.micro.59.030804.121316

Ivashuta S., Imai R., Uchiyama K., Gau M., and Shimamoto Y., 2002, Changes in chloroplast FTSH-like gene during cold acclimation in alfalfa (Medicago sativa), Journal of Plant Physiology, 159(1): 85-90 https://doi.org/10.1078/0176-1617-00661

Jayasekera M.M., Foltin S.K., Olson E.R., and Holler T.P., 2000, Escherichia coli requires the protease activity of FTSH for growth, Archives of Biochemistry \& Biophysics, 380(1): 103-107 https://doi.org/10.1006/abbi.2000.1903

Ji W.Q., Yan J.P., Bai X., Qiao P., Li Z.P., Yang Y.W., Guan W., and Zhao T.C., 2019, Functional analysis of the gene FTSH in Acidovorax citrulli, Plant Pathology, 49(4): 488-499

Kato Y., Kouso T., and Sakamoto W., 2012, Variegated tobacco leaves generated by chloroplast FTSH suppression: Implication of FTSH function in the maintenance of thylakoid membranes, Plant Cell Physiology, 53: 391-404 https://doi.org/10.1093/pcp/pcr189

Kato Y., and Sakamoto W., 2018, FTSH Protease in the thylakoid membrane: physiological functions and the regulation of protease activity, Frontiers in Plant Science, 9: 855 https://doi.org/10.3389/fpls.2018.00855

Kato Y., and Sakamoto W., 2019, Phosphorylation of the chloroplastic metalloprotease FTSH in Arabidopsis characterized by Phos-Tag SDS-PAGE, Frontiers in Plant Science, 10: 1080 https://doi.org/10.3389/fpls.2019.01080

Kamata T., Hiramoto H., Morita N., Shen J.R., Mann N.H., and Yamamoto Y., 2005, Quality control of Photosystem II: an FTSH protease plays an essential role in the turnover of the reaction center D1 protein in Synechocystis PCC 6803 under heat stress as well as light stress conditions, Photochemical \& Photobiological sciences, 4(12), 983-990 https://doi.org/10.1039/b506068k

Kihara A., Akiyama Y., and Ito K., 1997, Host regulation of lysogenic decision in bacteriophage lambda: transmembrane modulation of FTSH (HflB), the cII degrading protease, by HflKC (HflA), Proceedings of the National Academy of Sciences of the United States of America. USA, 94: 5544-5549 https://doi.org/10.1073/pnas.94.11.5544

Kihara A., and Ito K., 1998, Translocation, folding, and stability of the HflKC complex with signal anchor topogenic sequences, Journal of Biological Chemistry, 273(45): 29770-29775 https://doi.org/10.1074/jbc.273.45.29770

Knight C.A., Vogel H., Kroymann J., Shumate A., and Mitchell-Olds T., 2006, Expression profiling and local adaptation of Boechera holboellii populations for water use efficiency across a naturally occurring water stress gradient, Molecular Ecology, 15(5), 1229-1237 https://doi.org/10.1111/j.1365-294X.2006.02818.x

Lindahl M., Tabak S., Cseke L., Pichersky E, Andersson B, and Adam Z., 1996, Identification, characterization, and molecular cloning of a homologue of the bacterial FTSH protease in chloroplasts of higher plants, Journal of Biological Chemistry, 15, 271(46): 29329-29334 https://doi.org/10.1074/jbc.271.46.29329

Ling Q.H., Broad W., Trösch R., Töpel M., Sert T.D., Lymperopoulos P., Baldwin A., and Jarvis R.P., 2019, Ubiquitin-dependent chloroplast-associated protein degradation in plants, Science, 363(6429):eaav4467 https://doi.org/10.1126/science.aav4467

Nishimura K., Kato Y., and Sakamoto W., 2016, Chloroplast Proteases: Updates on proteolysis within and across suborganellar compartments, Plant Physiology, 171(4): 2280-2293

https://doi.org/10.1104/pp. 16.00330 
Ogura T., and Wilkinson A.J., 2001, AAA+ superfamily ATPases: common structure--diverse function, Genes to Cells, 6(7): 575-597 https://doi.org/10.1046/j.1365-2443.2001.00447.x

Schumann W., 1999, FTSH - a single-chain charonin? FEMS Microbiology Reviews, 23(1): 1-11 https://doi.org/10.1016/S0168-6445(98)00024-2

Seo S., Okamoto M., Iwai T., Iwano M., Fukui K., Isogai A., Nakajima N., and Ohashi Y., 2000, Reduced levels of chloroplast FTSH protein in tobacco mosaic virus-infected tobacco leaves accelerate the hypersensitive reaction, Plant Cell, 12(6): 917-932 https://doi.org/10.1105/tpc.12.6.917

Sun A.Q., Yi S.Y., Yang J.Y., Zhao C.M., and Liu J., 2006a, Identification and characterization of a heat-inducible FTSH gene from tomato (Lycopersicon esculentum Mill.), Plant Science, 170: 551-562 https://doi.org/10.1016/j.plantsci.2005.10.010

Sun A.Q., Yang J.Y., Yi S.Y., Zhao C.M., and Liu J., 2006b, Cloning and molecular characteristic of the metalloprotease gene LeFTSH6 from tomato. Journal of Plant Physiology \& Molecular Biology, 32(1): 64-72

Wang Q. L., Chen J. H., He N. Y., and Guo F. Q., 2018a, Metabolic reprogramming in chloroplasts under heat stress in plants, International journal of molecular sciences, 19(3): 849 https://doi.org/10.3390/ijms19030849

Wang T., Li S.H., Chen D., Xi Y., Xu X.Z., Ye N.H., Zhang J.H., Peng X.X., and Zhu G.H., 2018b, Impairment of FTSHi5 function affects cellular redox balance and photorespiratory metabolism in Arabidopsis, Plant \& cell physiology, 59(12): 2526-2535 https://doi.org/10.1093/pcp/pcy174

Wang X., Dinler B.S., Vignjevic M., Jacobsen S., and Wollenweber B., 2015, Physiological and proteome studies of responses to heat stress during grain filling in contrasting wheat cultivars, Plant Science, 230: 33-50 https://doi.org/10.1016/j.plantsci.2014.10.009

Yoshioka M., Uchida S., Mori H., Komayama K., Ohira S., Morita N., Nakanishi T., and Yamamoto Y., 2006, Quality control of photosystem II. leavage of reaction center D1 protein in spinach thylakoids by FtsH protease under moderate heat stress, Journal of Biological Chemistry, 281(31): 21660-21669 https://doi.org/10.1074/jbc.M602896200

Yin Z.T., Meng F.F., Song H.N., Wang X.L., Chao M.N., Zhang G.Z., Xu X.M., Deng D.X., and Yu D.Y., 2011, GmFTSH9 expression correlates with in vivo photosystem II function: chlorophyll a fluorescence transient analysis and eQTL mapping in soybean, Planta, 234(4): 815-827 https://doi.org/10.1007/s00425-011-1445-5

Zaltsman A., Feder A., and Adam Z., 2005, Developmental and light effects on the accumulation of FTSH protease in Arabidopsis chloroplasts - implications for thylakoid formation and photosystem II maintenance, Plant Journal, 42: 609-617 https://doi.org/10.1111/j.1365-313X.2005.02401.x

Zhang J.D., and Sun A.Q., 2009, Genome-wide comparative analysis of the metalloprotease FTSH gene families between Arabidopsis thaliana and rice, Chinese Journal of Biotechnology, 25(9): 1402-1408

Zheng C.H., Kong X.Y., Sui J.M., Shu C., and Zhao C.M., 2016, Identification, classification and salt stress expression analysis of metalloproteinase FTSH family in peanut (Arachis hypogaea L.), Journal of Jiangsu Agricultural Sciences, 44(12):74-77 